\title{
Manifestações e aglomerações em períodos de pandemia por COVID-19 Manifestações em períodos de pandemia
}

\section{Tiago Mendonça de Oliveira ${ }^{1}$}

Uma doença de caráter respiratório iniciou-se em dezembro de 2019 na cidade de Wuhan, província de Hubei na China e se espalhou rapidamente por todo país e para outras partes do mundo [1]. O surgimento do vírus COVID-19 levou a uma pandemia, colocando desafios notáveis na vigilância e controle da doença. Até o dia 03 de maio de 2020, a OMS havia registrado 3,3 milhões de casos, com 82,7 mil casos novos e um total de 238 mil mortes [2]. Boa parte dos casos são assintomáticos ou apresentam sintomas leves, mas uma parcela de infectados precisará de leitos de Unidade de Terapia Intensivo (UTI) $[3,4]$.

Há uma discussão com relação ao pico epidêmico de COVID-19 no Brasil, no entanto ainda existem grandes incertezas, pois a distribuição viral não é homogênea em um país de dimensão continental e devido ao isolamento social adotado por cada estado brasileiro. Porém, tem se observado uma disseminação crescente e rápida sobre a população, além de uma interiorização dos casos no país. No Brasil, até o dia 03 de maio de 2020, tínhamos registrado 101,1 mil casos, com 4.588 novos casos e um total de 7.025 mortes [5]. Para Villela [6], países como o Brasil que possuem graves disparidades sociais e iniquidades em saúde pública é necessário foco, planejamento e controle, a fim de reduzir as desigualdades assistenciais em populações vulneráveis e evitar o contágio pelo COVID-19. O Brasil como outros países tem apresentado dificuldades de assistência e controle da epidemia pelo COVID-19.
Alguns fatores merecem destaque, como a falta de EPIs para profissionais de saúde, interiorização dos casos e aumento de casos em regiões de maior vulnerabilidade social $[1,6,7,8]$. Somado a isso, as questões políticas e as discussões do relaxamento das medidas de isolamento social têm ganhado destaque desencadeado algumas manifestações e aglomerações por todo país.

No mês de abril de 2020, ao menos duas vezes (05/04 e 19/04) ocorreram manifestações políticas e contrárias ao isolamento social. No dia 03 de maio, ocorreu outra manifestação com os mesmos propósitos. Estas aglomerações são contrárias as orientações do Ministério da Saúde e da Organização Mundial da Saúde, que reiteram que o isolamento social reduz a curva de contágio e surgimento de novos casos. Com base nas proposições anteriores, foi construído um gráfico (Figura 1) considerando o número de casos antes, no dia e duas semanas após as manifestações. Estes dados referem-se ao Distrito Federal e Plano Piloto (local onde ocorreram as aglomerações), além disso foi feita uma possível projeção para o dia 17/05 com os possíveis novos casos [9]. A projeção foi estimada para o crescimento médio de novos casos, baseando-se em semanas anteriores. O número projetado pode ficar abaixo ou acima da média, de acordo com a taxa de isolamento social, aumento da testagem e devido as medidas impostas pelos órgãos governamentais no combate a pandemia.

\footnotetext{
${ }^{1}$ Departamento de Medicina Veterinária Preventiva/Epidemiologia da Escola deVeterinária, Universidade Federal de Minas Gerais, Belo Horizonte, Brasil.

E-mail: tiago0725@gmail.com.
}

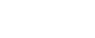




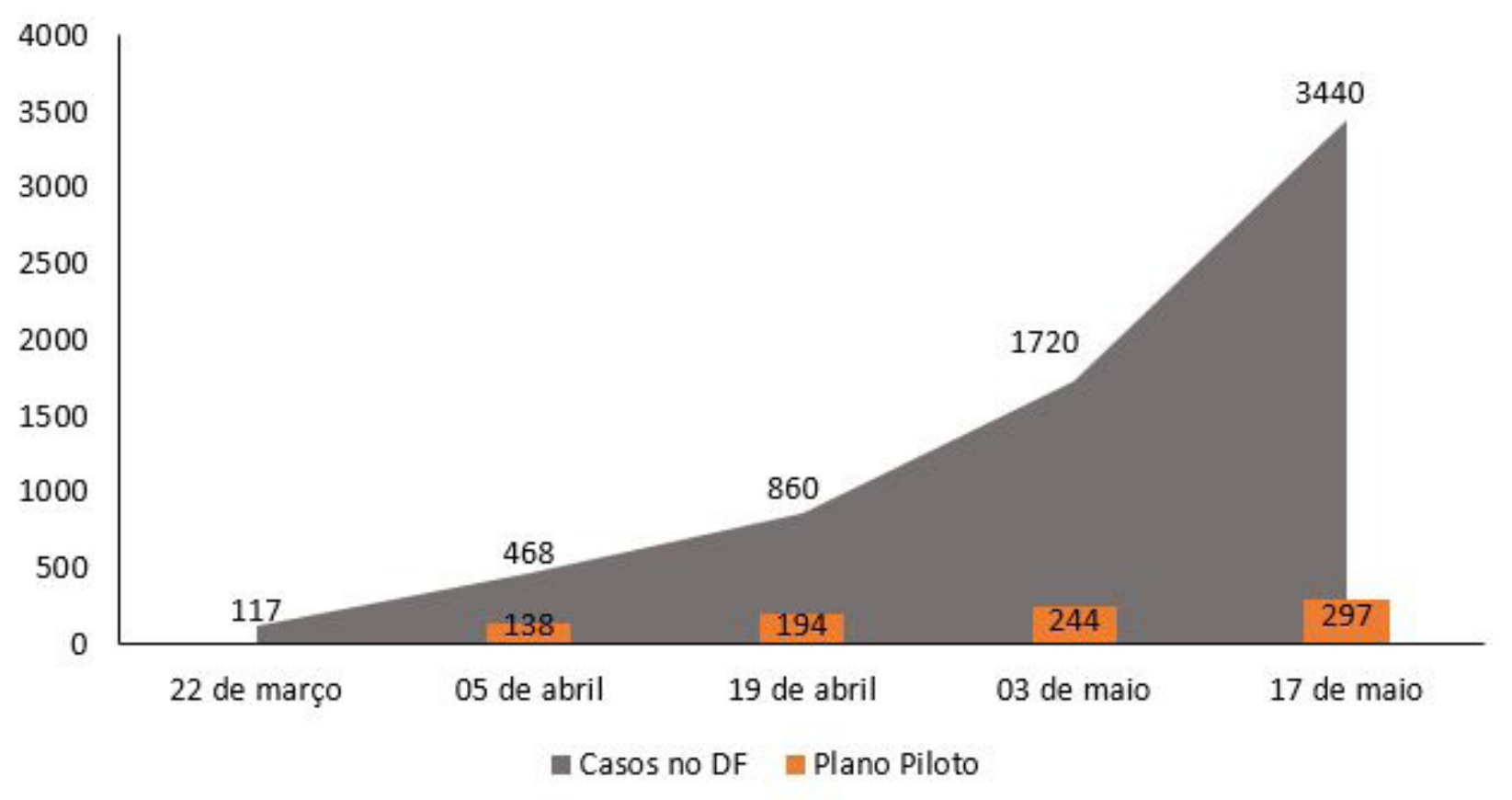

Figura 1. Casos confirmados e projeção para CoviD-19 no Distrito Federal.

Observou-se que os números de casos quase dobram a cada duas semanas, estes números podem demonstrar o quanto estas aglomerações podem contribuir na disseminação da doença. No Plano Piloto, local onde ocorreram as aglomerações constatou-se que a cada duas semanas em média surgem mais 53 novos casos confimados. Estes números são baseados a nenas em casos confirmados, ou seja, detectados pelos sistemas

de saúde, no entanto tem se observado uma elevada taxa de subnotificações. Em uma situação hipotética se tivéssemos 10 pessoas assintomáticas na manifestação, elas seriam capazes de transmitir em média a mais 3 pessoas [10], na cadeia de transmissão teríamos 30 pessoas infectadas (Figura 2). Na sequência essas pessoas votores do COVID-19 ao longo da cadeia de transmissão espalhando a mais pessoas.

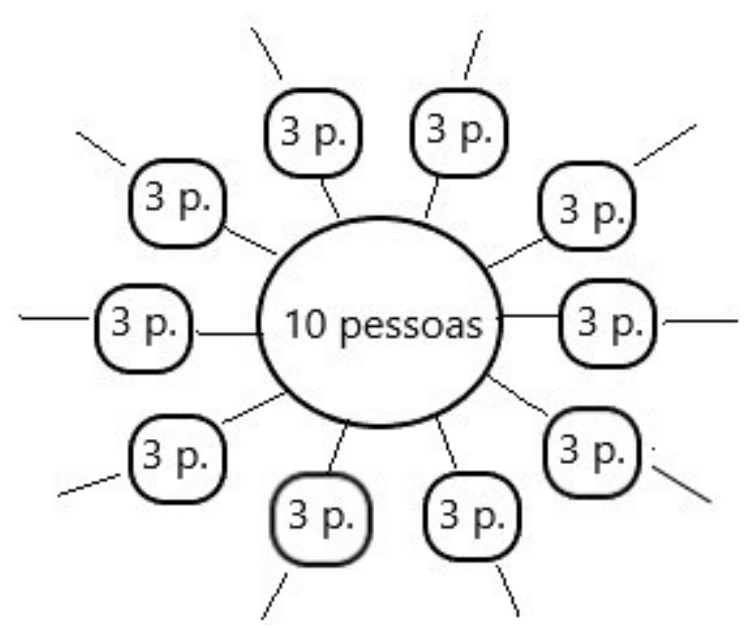

Figura 2. llustração da situação hipotética cadeia de transmissão do COVID-19
Com base nessas informações, fica claro que e preciso investir no isolamento social e na diminuição do deslocamento das pessoas para auxiliar na reduça de novos casos [11]. A adesão por parte da população pelo isolamento social poderia minimizar os impactos das internações dos casos graves, evitando a superlotação dos leitos de UTI.

\section{CONCLUSÃO}

É preciso aumentar a testagem dos casos para melhor a sensibilidade da vigilância em saúde, a fim de melhorar o direcionamento das ações e delinear novas estratégias de controle da doença no Brasil. Além disso, sugere-se que os órgãos de saúde possam subsidiar açõe políticas locais para diminuição do deslocamento e que o poder judiciário possa tomar medidas cabíveis, a fim de evitar aglomeraçōes nos estados brasileiros e possiveis disseminações virais.

\section{REFERÊNCIAS}

1. Wang C, HorbyPW, HaydenFG, Gao GF. Anovelcoronavirus outbreak of global health concern. The lancet. 2020, p.470 473. https://doi.org/10.1016/50140-6736(20)30185-9

2. World Health Organization Coronavirus disease (COVID-2019) situation reports 104. Disponível em: < https://www.who.int/docs/default-source/coronaviruse/ situation-reports/20200503-covid-19-sitrep-104. pdf?sfvrsn=53328f46_2> Acesso: em 03 de maio de 2020 .

3. Yu X., Yang R. COVID®19 transmission through asymptomaticcarriersisachallengetocontainment. Influenza Other Respiratory Viruses. 2020. doi:10.1111/irv12743

4. Lipsitch M, Phil D, Swerdlow, DL, Finelli L. Defining the Epidemiology of Covid-19 - Studies Needed. The New England Journal of Medicine. 2020, v. 382 p.1194-1196 Disponível em: < https://www.nejm.org/ doi/pdf/10.1056/NEJMp2002125?articleTools=true Acesso: em 03 de maio de 2020 .

5. Brasil, Ministério da Saúde. Disponível em: <https:/ covid saude gov br/> Acesso: em 03 de maio de 2020
6. Villela DAM. The value of mitigating epidemic peaks of COVID-19 for more effective public health responses, Revista da Sociedade Brasileira de Medicina Tropical, (2020) v.53, e20200135.

7. Freitas ARR, Napimoga M, Donalisio MR. Análise da gravidade da pandemia de Covid-19. Epidemiologia e Serviços de Saúde. 2020, v.29, n. 2, e2020119. https://doi.org/10.5123/s1679-49742020000200008

8. Nota Técnica - MonitoraCovid-19 Tendências atuais da pandemia de Covid-19: Interiorização e aceleração da transmissão em alguns estados. 2020. Disponível em: < https://portal.fiocruz.br/sites/ portal.fiocruz.br/files/documentos/monitoracovid notatecnica_28_04.pdf> Acesso: em 03 de maio de 2020. 9. Boletins Informativos DIVEP/SVS Disponível em: $<\quad$ http://www.saude.df.gov.br/boletinsinformativosAcesso: em 03 de maio de 2020

10. Li Q, Guan X, Wu P, et al. Early Transmission Dynamics in Wuhan, China, of Novel Coronavirus-Infected Pneumonia. The New England Journal of Medicine. 2020, v.382, n.13, p.1199-1207. DOI: 10.1056/NEJMoa2001316

11. Moritz UG Kraemer MUG; Chia-Hung Y; Gutierrez B; Wu CH; Klein B; Pigott DM; et al. The effect of human mobility and control measures on the COVID-19 epidemic in China. Science (2020) DOI: 10.1126/science.abb4218 